\title{
La excepcionalidad de la contratación menor
}

\section{Pablo Velázquez Navarrete}

Funcionario de Carrera del Cuerpo Sup. de Administradores (esp. Gestión Financiera) de la Junta de Andalucía. Ldo. en Economía por la Universidad de Granada, Máster en Dirección pública, políticas públicas y tributación por I.E.F.-U.N.E.D.

\section{RESUMEN.}

Consciente de las rigideces que imponen otros tipos de procedimientos de contratación administrativa, el legislador español siempre ha entendido necesario dotar a la Administración de una figura contractual que le permita ahorrar trámites y obviar requisitos en favor de la celeridad al satisfacer una necesidad pública: el contrato menor. Esta vía de contratación, por adjudicación directa, supone no obstante una ruptura en los principios generales de publicidad, concurrencia y competencia, y su empleo masivo un empeoramiento de los costes y rendimientos del gasto público. El uso fraudulento y el abuso que de este contrato administrativo han hecho muchos gestores ha reavivado, en los últimos años, el debate sobre la conveniencia de su mantenimiento.

PALABRAS CLAVE:

Menor - Contrato - Administración - Abuso - Competencia

ABSTRACT.

Aware of the rigidities imposed by other types of government procurement procedures, the Spanish legislator has always understood necessary to provide the Administration with a contractual figure to simplify procedures and obviate requirements as to increase the speed in meeting public needs: the minor contract. This way of direct award procedure however marks a break in the general principles of publicity, concurrence and competition. In addition, its massive utilization may cause higher costs and lower performance in public spending. The misuse and abuse of the minor contract by many public managers has revived the recent debate on the appropriateness of its existence. 
KEY WORDS:

Minor - Contract - Administration - Abuse - Competition

Desde el siglo XIX hasta la actualidad el legislador siempre creyó necesario dotar a la Administración de una figura contractual que le permitiera ahorrar trámites y obviar requisitos en favor de la celeridad en la consecución del objeto del contrato, aún a costa de arriesgar una merma significativa de competencia entre licitadores y consecuentemente un empeoramiento de costes y rendimientos.

\section{ORIGEN DEL GONTRATO MENOR Y PERVIVENGIA EN LA NORMA}

El Real Decreto de 27 de febrero de 1852, de Bravo Murillo, que completaba la Ley de Administración y Contabilidad de 1850, supone la primera referencia histórica a la contratación pública. Como queda reflejado en su Exposición de Motivos al fijar la subasta como modo general de adjudicación, el Gobierno ya buscaba entonces "establecer ciertas trabas saludables, evitando los abusos fáciles de cometer en una materia de peligrosos estímulos y de garantizar la Administración contra los tiros de la maledicencia". Consciente de la particularidad de la contratación pública, de su peso económico y de su problemática, se dieron así los primeros pasos para limitar las malas prácticas de autoridades y funcionarios en la adjudicación del gasto público, los sobornos y la falta de competencia entre los licitadores. Al objeto de primar la publicidad de los procedimientos y la aplicación de criterios objetivos, favoreciendo la concurrencia de licitadores y su competencia real -ambas condiciones necesarias para optimizar la inversión del Estado- el Legislador dibujó un procedimiento general "por remate solemne y público, previa la correspondiente subasta" (con equivalencia actual en el procedimiento abierto). Y es que se estimó que la subasta constituía el método que más limitaciones presentaba al fraude en la actuación de los gestores, pese a que obviaba otros criterios relevantes de valoración aparte del precio, como la calidad de los bienes suministrados.

Sin embargo, también desde 1852 nuestra legislación ha contemplado ininterumpidamente, con las obvias adaptaciones, ciertas excepciones al procedimiento general para determinados contratos por razón de su importe. En su art. 6 este Real Decreto ya planteaba a los gestores públicos la posibilidad de la adjudicación directa obviando "solemnidades de la subasta", para contratos de determinados importes y bajo ciertas circunstancias. Posteriormente la Ley de Contabilidad y Hacienda de 1911 consagró la adjudicación directa, al reconocerla como una de las tres vías permitidas para adjudicación de contratos públicos (la subasta, el concurso y la denomina- 
da "contratación libre"), prescindiendo esta última de "formalidades" exigibles a las restantes en materia de publicidad y concurrencia. Y lo cierto es que a lo largo del siglo XX la legislación española en materia contractual ha mantenido de una u otra manera la vía excepcional del contrato libre o menor. El planteamiento adoptado por el vigente Texto Refundido de la Ley de Contratos del Sector Público (TRLCSP), aprobado por RDL 3/2011, de 14 de noviembre, sobre la contratación menor es deudor de la Ley 13/1995, de 18 de mayo, de Contratos de las Administraciones Públicas, que aspiraba a simplificar la contratación a través de la misma. A la vista del borrador de Anteproyecto de la nueva Ley de Contratos del Sector Público, publicado por la Dirección General de Patrimonio del Estado el 17 de abril de 2015 para someterse a información pública y que viene a reiterar lo dispuesto en sus antecedentes, tampoco cabe esperar cambios significativos en su regulación.

\section{LA VENTAJOSA TRAMITACIÓN SIMPLIFICADA DEL EX- PEDIENTE DE GONTRATACIÓN MENOR}

En comparación con otros procedimientos de adjudicación de contratos públicos, la contratación menor es excepcional y viene fundamentada en la cuantía del contrato. Con la meta de dotar de la mayor velocidad posible a la tramitación de los contratos menores, la ley únicamente establece dos requisitos procedimentales: aprobación del gasto y factura. Así lo ratifica el Informe 9/2009, de 15 de junio, de la Junta Consultiva de Contratación Administrativa del Estado (JCCA), que al tratar el contrato menor dice que "el descrito régimen legal configura, claramente, un tipo contractual de tramitación excepcional, que se limita a exigir, como regla general, la aprobación del gasto y la incorporación al expediente de la factura correspondiente, omitiéndose toda referencia al cumplimiento del resto de requisitos de tramitación de los contratos administrativos contenidos en el Título Primero del Libro II de la Ley de Contratos del Sector Público". Sencillamente pocas exigencias en la tramitación, enmarcadas -eso sí- en unas exigencias al gasto (importe, duración) que el órgano de contratación debe respetar inexcusablemente. De hecho, y como apunta el experto en Derecho Público Pedro Llinares Cerveral, "el contrato menor es un supuesto de adjudicación directa sin obligación de justificar qué criterios se han seguido para adjudicar el contrato".

${ }^{1}$ Llinares Cervera, Pedro (2009): Algunas consideraciones sobre los criterios de adjudicación en la Ley 30/2007, de 30 de octubre, de contratos del sector público, a la luz del Derecho comunitario, Contratación Administrativa Práctica. Revista de la contratación administrativa y de los contratistas, núm.82, Pps. 38-39. 
Así las cosas la citada Ley 13/1995, de 18 de Mayo, en vigor hasta el 22 de junio de 2000, llegaba a afirmar que la contratación menor ayudaría a "conseguir una Ley de Contratos de las Administraciones Públicas que responda adecuadamente a las necesidades que la situación de la contratación pública exige actualmente en los distintos aspectos contemplados". El punto 2.6 de su Exposición de Motivos, al abordar la necesaria agilización de trámites para contratar determinadas actuaciones, estimaba que eran "dignas de mencionarse" medidas introducidas como la "potenciación de los contratos menores". En otras palabras, en adelante se aceptaría un empleo intensivo del contrato menor - a priori algo excepcional- en la Administración.

\section{EL CONTRATO MENOR Y EL DEREGHO EUROPEO}

El derecho de la Unión Europea, verdadera guía del marco normativo nacional, tolera a regañadientes la figura del contrato menor, y en general comprende mal cualquier modo de adjudicación directa. El catedrático de Derecho Administrativo José Antonio Moreno Molina² recuerda que "en el Derecho comunitario de la contratación pública no se reconoce la figura del contrato menor, definida en la ley española exclusivamente por la cuantía del contrato, ni tampoco se recogen dentro de los supuestos tasados de utilización del procedimiento negociado aquellos que permiten en la Ley de Contratos del Sector Público acudir a este procedimiento solo por razón de su valor. El propio Tribunal de Justicia de la Unión Europea ha calificado la celebración ilegal de contratos de adjudicación directa como la infracción más grave del Derecho comunitario en materia de contratos públicos, y se ha lamentado de que las Directivas sobre recursos en vigor no permiten prevenir o corregir de manera eficaz las consecuencias de dicha ilegalidad (TSJUE de 11 de enero de 2005 (Stadt Halle), apartado 37 “". Al abordar más concretamente la figura de los contratos menores, no podemos sino compartir su opinión de que todos los objetivos consagrados en el art. 1 de la Ley de Contratación del Sector Público "quedan en entredicho si los órganos de contratación deciden -como hasta ahora vienen haciendo masivamente nuestras Administraciones- utilizar la figura del contrato menor, seleccionando libremente al contratista", pues obviamente la utilización abusiva del contrato menor viola nítidamente los principios generales de la contratación administrativa. ${ }^{3}$

\footnotetext{
2 Yáñez Sánchez, Guillermo (2009): Los contratos menores y la publicidad y concurrencia de empresas. Comunidad de prácticas de la contratación pública.

${ }^{3}$ Candela Talavero, José Enrique (2011): El fraccionamiento del objeto de los contratos públicos y la fraudulenta utilización del contrato menor, Auditoría Pública, nº 53, Pps. 85-94.
} 
No es de extrañar así que, como advierte la Comisión Consultiva de Contratación Pública de Andalucía, el Tribunal de Justicia europeo sentenció sobre el uso del procedimiento negociado sin publicación previa de anuncio de licitación -y creo que de manera extensible a todas las adjudicaciones directas- que "el artículo 11, apartado 3, de la Directiva 92/50, que prevé este procedimiento, como disposición que autoriza una excepción a las normas que pretenden garantizar la efectividad de los derechos reconocidos por el Tratado C.E. en el sector de los contratos públicos de servicios, debe ser objeto de una interpretación estricta, y que la carga de la prueba de que existen realmente las circunstancias excepcionales que justifican la excepción incumbe a quien quiera beneficiarse de ella (sentencia de 10 de abril de 2003, Comisión/Alemania, asuntos acumulados C-20/01 y C-28/01, Rec. p. I3609, apartado $58)^{64}$.

\section{LA QUIEBRA DE LOS PRINGIPIOS GENERALES DE CON- TRATACIÓN PÚBLICA}

El Libro Verde sobre la modernización de la política de contratación pública de la Unión Europea ${ }^{5}$ sentencia que, a través de la contratación, debe asegurarse el incremento "en la eficiencia del gasto público", lo que conlleva de un lado "buscar los mejores resultados posibles de la contratación (la máxima rentabilidad de las inversiones)" y de otro "la racionalización de los procedimientos de contratación, con medidas de simplificación específicamente adaptadas a las necesidades particulares" de los pequeños poderes adjudicadores, lo que ayudaría a los gestores públicos a lograr "los mejores resultados posibles de la contratación con la menor inversión posible, en términos de tiempo y de dinero público". Para alcanzar este objetivo la Comisión Europea subraya la necesidad de propiciar "la competencia más fuerte posible por los contratos públicos que se adjudican en el mercado interior", para lo que "se debe dar a los licitadores la oportunidad de competir en condiciones equitativas y deben evitarse los falseamientos de la competencia”. En relación con los contratos públicos inferiores a los umbrales previstos en las Directivas, como los contratos menores, el punto 3.28 del Libro Verde de la contratación pública en la Unión Euro-

\footnotetext{
${ }^{4}$ Comisión Consultiva de Contratación Pública, Dirección General de Patrimonio, Consejería de Hacienda y Administración Pública de la Junta de Andalucía (2015): Contratación Pública. Jurisprudencia del TJUE. Pps. 26-27.

${ }^{5}$ Comisión Europea (2011). Libro Verde sobre la modernización de la política de contratación pública de la UE, Hacia un mercado europeo de la contratación pública más eficiente, pp 3.
} 
pea: reflexiones para el futuro $(1996)^{6}$ dispone que "los procedimientos previstos por las Directivas comunitarias son aplicables exclusivamente a los contratos públicos de un importe estimado superior a los umbrales establecidos (los sujetos a regulación armonizada, o S.A.R.A.). Algunos poderes adjudicadores consideran que los contratos públicos que no alcanzan estos umbrales no están sometidos a ninguna disposición comunitaria, de manera que en ocasiones estos contratos se adjudican sin haber convocado previamente un concurso público. Muchos de estos contratos son de una importancia considerable, en particular para la pequeña y mediana empresa. Al igual que el otorgamiento de concesiones y contratos similares, la adjudicación de estos contratos debe efectuarse respetando las disposiciones del Tratado C.E. sobre la libre circulación de las mercancías y servicios y los principios fundamentales de no discriminación, igualdad de trato y transparencia, que se hallan en su base". La figura del contrato menor, sin embargo, se conjuga mal con lo anterior en cuanto minimiza, si no anula, la posible competencia entre licitadores, si no formalmente desde luego sí de facto.

Se reconoce pues la distorsión que la contratación menor introduce en el modelo. Y es que como se apunta acertadamente desde la Comisión Nacional de los Mercados y la Competencia (CNMC) "una competencia adecuada entre licitadores comporta unos resultados más favorables en términos de menor precio y mayor calidad para el órgano adjudicador, y por tanto para el interés general"; "unas condiciones de competencia deficientes conllevan un mayor esfuerzo económico para las entidades del sector público que contratan bienes y servicios y por tanto para los ciudadanos"7. Uno de los presidentes de la institución, Luis Berenguer, ilustró taxativamente el problema al dar a conocer que las licitaciones públicas restrictivas a la competencia, solo en el año 2011, representarían un extracoste de más de 3.000 millones de Euros al erario público (estatal). Según estimaciones de la Comisión hasta el 10 por ciento de las licitaciones de contratos en ese ejercicio, por valor de unos 15.000 millones de Euros, presentaba "defectos o restricciones a la competencia"8. En términos análogos se expresaba la Intervención General del Estado ${ }^{9}$ cuando afirmaba, en relación con el resultado de sus actuaciones de control financieros permanentes a

\footnotetext{
${ }^{6}$ Comisión Europea (1996): Libro verde. La contratación pública en la Unión Europea: reflexiones para el futuro.

${ }^{7}$ Comisión Nacional de los Mercados y la Competencia (2009): Guía sobre Contratación Pública y Competencia, Pp. 5-6.

${ }^{8}$ Agencia Efe (07 de febrero de 2011). Las deficiencias en la contratación pública cuestan 3.000 millones a las arcas públicas, según la CNC. Expansión.

${ }^{9}$ IGAE, Ministerio de Economía y Hacienda (2009): Informe general sobre los principales resultados de la ejecución de los planes de control financiero permanente y auditoría pública del ejercicio 2008. Pps. 27-29.
} 
organismos de la Administración General del Estado en el ejercicio 2008, que el 40\% de los informes de control a ministerios y el 20\% de los demás organismos y entes manifestaban que se estaban produciendo claros fraccionamientos de contrato en procedimientos negociados y contratación menor.

\section{LA CONTRATACIÓN MENOR EN EL CONTEXTO DE LA NUEVA GESTIÓN PÚBLICA}

La nueva gestión pública ${ }^{10}$ exige a la Administración eficacia, adaptabilidad y flexibilidad, siempre con la meta última de la eficiencia en el gasto público, que todos compartimos. A la vez, y como necesario requisito para permitir la consecución del objetivo anterior, el sector público tiene que asegurar la existencia de competencia entre sus licitadores, lo que obligatoriamente pasa por una libre y fluida concurrencia en términos de igualdad. Ahora bien, la consecución de este punto impone unos procedimientos invariables de contratación que cuenten con la suficiente publicidad de la licitación y garanticen un juicio objetivo en la selección del candidato más ventajoso para el interés público, lo que alarga plazos e introduce rigideces en el sistema. En consecuencia se le pide al gestor público satisfacer ágilmente necesidades de servicio, obra o suministro, cada vez más dinámicas y cambiantes, dentro de un férreo corsé procedimental impuesto por la normativa a fin de acotar actuaciones negligentes o dolosas, o sencillamente que perjudican la competencia en el mercado. En términos coloquiales a la Administración se le demanda ir más rápido pero sin soltar el peso atado a sus tobillos, sin duda una fuente de frustración que como gestores muchos de nosotros habremos experimentado en nuestro trabajo diario. Justamente en esta encrucijada encontramos al contrato menor por razón de su importe.

La tensión entre la celeridad del procedimiento y el debido respeto a las garantías del mismo, aunque no es exclusiva de la contratación administrativa, en el ámbito de los procedimientos de adjudicación "se manifiesta muy claramente", como indica José Miguel Carbonero Gallardo (2010). En la conclusión de su interesante tesis doctoral sobre la adjudicación de los contratos administrativos, Carbonero apunta acertadamente que "en todos ellos (los procedimientos de adjudicación) se pretende el mejor equilibrio entre varias finalidades: la garantía de la objetividad en la Administración, la consecución de la mejor oferta posible para la ejecución del

\footnotetext{
${ }^{10}$ García Sánchez, Isabel Ma (2007): La nueva gestión pública: evolución y tendencias. Presupuesto y Gasto Público, no 47. Pps. 37-64.
} 
contrato, y la articulación de todo ello en un procedimiento administrativo lo más ágil posible en términos de tiempo para el órgano de contratación". Con eso y todo sigue sin ser suficiente para el gestor.

Los procedimientos de adjudicación directa se convierten así en indispensables, según Francisco Blanco López ${ }^{11}$, dado que "el resto de procedimientos tienen un tempo de tramitación absolutamente insoportable que colocan a la contratación administrativa española en el paradigma del formalismo jurídico, la parafernalia procesal y la quiebra clamorosa de la eficiencia administrativa". Si, por ejemplo, se llevara a cabo de forma escrupulosa el procedimiento negociado (sin ir más lejos, negociando), Blanco asevera que se podría producir un verdadero "colapso procesal" al privar a los órganos de contratación de un procedimiento de adjudicación ágil y flexible para contratos de cuantía inferior a los topes de los S.A.R.A., y que justamente por ello ningún órgano consultivo general o especializado en materia de contratación administrativa ha publicado instrucciones generales que establezcan claramente los criterios para desarrollar las negociaciones. Claro está que este tipo de procedimiento de adjudicación está pensado para expedientes en los que realmente se necesita negociar con los licitadores, y otra cuestión muy distinta es el reto de la simplificación y agilización procedimental en los expediente de contratación administrativa. La contratación menor, por su lado, comparte ese matiz: la búsqueda de la flexibilidad y rapidez en el procedimiento, que sí se logra sin duda con el menor, no puede ser la única motivación para su uso continuado.

Sea como fuere se constata que desde sus orígenes la figura del menor constituye una meridiana anormalidad - aun ajustada a derecho- y que debe ser tratada como tal. Su uso debe circunscribirse a circunstancias excepcionales que, persiguiendo más agilidad burocrática en pos del interés público, desaconsejen seguir otros procedimientos de contratación que sí cuenten con la adecuada publicidad. Y tales circunstancias debieran constar en la justificación de la elección del procedimiento y de los criterios de adjudicación según el art. 109.4 del TRLCSP. No obstante el procedimiento ni viene exigiendo al órgano contratante concretar esas especiales circunstancias que soporten la selección del contrato menor, como por ejemplo reconoce el Tribunal Vasco de Cuentas Públicas al fiscalizar las cuentas del Ayuntamiento de Bil-

11 Blanco Pérez, Francisco (2011): El procedimiento negociado de adjudicación de los contratos administrativos. La negociación como elemento esencial y configurador del procedimiento. Contratación administrativa práctica: Revista de la contratación administrativa y de los contratistas $\mathrm{n}^{\circ} 111$. 
bao de $2010^{12}$. En realidad se acepta como único motivo de selección de esta vía de contratación la cuantía de los trabajos, que se recogerá en una posible memoria justificativa del gasto que ni siquiera es de aporte obligatorio a la Intervención por parte del gestor, y eso que es sumamente decisivo para clarificar la cuestión del objeto del contrato y su posible fraccionamiento ilícito. El Tribunal Administrativo Central de Recursos Contractuales ha subrayado como principio básico de la contratación del sector público la "eficiente utilización de los fondos públicos" (Resolución n 247/201), y como consecuencia cobra precisamente razón de ser el principio general de la prohibición del fraccionamiento del objeto del contrato pues "conduce a evitar la vulneración en el expediente de la contratación pública de los principios de la publicidad y concurrencia de la contratación pública”. A fin de cuentas se persigue impedir que al fraccionar el objeto contractual en el ámbito público puedan eludirse ciertas normas exigibles para contratos superiores a determinado importe: publicidad y tipo de procedimiento de adjudicación aplicable. Es ésta la doctrina de la JCGA del Estado, como reconoce por ejemplo en su Informe $n^{\circ} 7 / 12$ de mayo de 2013. Más si cabe en un escenario en que se exime a los gastos ejecutados bajo menores de fiscalización previa... Y es que no olvidemos que la confluencia de tales excepciones en los cauces habituales de tramitación y fiscalización puede acabar favoreciendo aún más ciertas malas prácticas del gestor público en la selección de esta forma de contrato, que recordemos es además potencialmente contraria a la competencia entre empresas y que no facilita la libre concurrencia de licitadores.

\section{LOS GESTORES Y EL FRAUDE EN LOS EXPEDIENTES DE CONTRATAGIÓN MENOR}

Asumido el difícil contexto en que se desarrolla la gestión pública hoy en día, no podemos olvidar que la contratación menor es atractiva para los órganos adjudicadores por la flexibilidad y agilidad que aporta, pero también por simple comodidad o a lo peor para favorecer a determinados empresarios. Esta casuística es la que ha motivado la aparición de tanta literatura sobre la misma y generado abundantes informes y notas de los órganos fiscalizadores y consultivos en materia contractual.

La cuantía y duración son elementos que definen absolutamente el contrato menor, surgiendo el riesgo de que sencillamente se fraccione el objeto del mismo pa-

\footnotetext{
12 Acuerdo del Pleno del Tribunal Vasco de Cuentas Públicas de aprobación definitiva del Informe Ayuntamiento de Bilbao, 2010, adoptado en sesión de 8 de noviembre de 2012. Punto III.1.5.
} 
ra cumplir con lo marcado por la ley. Será el Órgano fiscalizador el que, con carácter posterior a la contratación y ejecución de los trabajos, deba entrar a valorar la cuestión crucial de si se dio el citado fraude de ley para forzar ese tipo de contratación. Desafortunadamente numerosos informes ${ }^{13}$ del Tribunal de Cuentas, Juntas Consultivas de Contratación Administrativa, Cámaras de Cuentas regionales o de Intervenciones Generales han puesto de manifiesto el más que frecuente fraccionamiento del objeto de contratos para adecuar los expedientes a los requisitos fijados por la ley en la contratación menor. No obstante, y pese a la importancia de esta forma de contrato, sigue existiendo un enorme margen de interpretación en aspectos determinantes de su calificación como tal, su importe y duración, particularmente apreciable en los supuestos de fraccionamiento del objeto del contrato.

La finalidad para la que se creó el contrato menor, y su misión inherente de ganar en sencillez y rapidez para una mejor gestión, ha forzado que quede dibujado en la Norma de una manera esquemática y libre de muchos de los trámites exigibles a otras formas de contratación, incluso en materia de fiscalización (exención de fiscalización previa), constituyendo una verdadera anormalidad. En este contexto de flexibilidad - más o menos acotada- se consolidaron entre los gestores públicos modos de operar contrarios al espíritu original de su nacimiento, constituyéndose como común moneda de cambio burdas ilegalidades - como la reiteración de terceros en prórrogas implícitas de contratos menores- o fraudes de ley, perjudicando la competencia con nefastas consecuencias en los precios a medio y largo plazo. Precisamente entre esos fraudes de ley hay que destacar el fraccionamiento ilícito del objeto del contrato para mantener el valor del expediente de contratación bajo los umbrales legales de la contratación menor.

\section{REFLEXIÓN FINAL}

Desconocemos si la figura del menor pervivirá en el largo plazo. Desde luego es nítido el interés de la Unión Europea por consagrar el principio de la competencia entre empresas como garantía fundamental de eficiencia y de que el mercado no se verá distorsionado vía precios, particularmente por la contratación pública dado su enorme volumen (el peso del gasto público en Andalucía en el ejercicio 2013 fue

13 Aranda Plaza, S., González Romera, Ma A. y Tena Ruíz, J. (2012): Texto refundido de la Ley de contratos del Sector Público. Normativa, sentencias, resoluciones, informes, consultas y dictámenes. Las Rozas (Madrid): La Ley-Wolters Kluwer España. 
del $18 \%$ del $\left.\mathrm{PIB}^{14}\right)$. Habiendo constatado que la contratación menor es campo abonado para prácticas irregulares, lo que queda particularmente a las claras en los numerosos casos de fraccionamiento ilícito del objeto del contrato publicados, el legislador debe cuestionarse hoy su propia existencia, comprometida por el espíritu de las normas europeas. Pero con mucha más inmediatez éste ha de revisar sus requisitos de tramitación y fiscalización. Es urgente tomar medidas para que los órganos de contratación entiendan, de una vez por todas, que el recurso a la contratación menor por razón del importe debe ser una rareza de la que no cabe abuso.

\section{BIBLIOGRAFÍA/WEBGRAFÍA}

Agencia Efe (07 de febrero de 2011): Las deficiencias en la contratación pública cuestan 3.000 millones a las arcas públicas, según la CNG. Expansión. (En línea). Recuperado de: http://www.expansion.com/2011/02/07/funcion-publica/1297095899.html

Aranda Plaza, S., González Romera, Ma A. y Tena Ruíz, J. (2012): Texto refundido de la Ley de contratos del Sector Público. Normativa, sentencias, resoluciones, informes, consultas y dictámenes. Las Rozas (Madrid): La Ley-Wolters Kluwer España.

Carbonero Gallardo, M. (2010). La adjudicación de los contratos administrativos: origen, evolución y sistema actual. Tesis doctoral inédita. Universidad de Granada, Facultad de Derecho, Granada.

García Sánchez, Isabel Mª (2007): La nueva gestión pública: evolución y tendencias. Presupuesto y Gasto Público, no 47. Pps. 37-64. (En línea). Recuperado de:

http://www.ief.es/documentos/recursos/publicaciones/revistas/presu_gasto_publico/47_GarciaSanchez.pdf

Blanco Pérez, F. (2011): El procedimiento negociado de adjudicación de los contratos administrativos. La negociación como elemento esencial y configurador del procedimiento. Contratación administrativa práctica: Revista de la contratación administrativa y de los contratistas, $\mathrm{n}^{\circ}$ 111. (En línea). Recuperado de: https://ecatalunya.gencat.cat/eCatRepository/download?fileId=40280e8c3dc3fofe013dcaef9f0102b5

Candela Talavero, J. E. (2011): El fraccionamiento del objeto de los contratos públicos y la fraudulenta utilización del contrato menor. Auditoría Pública, n 53. (PDF). Recuperado de: http://www.auditoriapublica.com/hemeroteca/pag\%2085\%20a\%2094.pdf

${ }^{14}$ Europa Press (09 agosto 2014): "Andalucía es de las mayores CCAA por gasto público sobre el PIB pero la de menos gasto público por habitante". Europa Press - Noticias. Recuperado en:

http://www.europapress.es/andalucia/sevilla-00357/noticia-andalucia-mayores-ccaa-gasto-publico-pib-menos-gasto-publico-habitante-20140809115320.html 
Comisión Europea (2011): Libro Verde sobre la modernización de la politica de contratación pública de la UE, Hacia un mercado europeo de la contratación pública más eficiente. (PDF). Recuperado de: http://eurlex.europa.eu/LexUriServ/LexUriServ.do?uri=COM:2011:0015:FIN:ES:PDF

Comisión Europea (1996): Libro verde, la contratación pública en la Unión Europea: reflexiones para el futuro. (PDF). Recuperado de:

http://es.scribd.com/doc/13851909/Libro-Verde-Contratacion-UE\#scribd

Comisión Nacional de los Mercados y la Competencia (2009): Guía sobre Contratación Pública y Competencia. (PDF). España. Recuperado de: http://www.cnmc.es/Portals/0/Ficheros/Promocion/Guias_y_recomendaciones/GUIA_CONTRATACION_v4.pdf

Comisión Nacional de los Mercados y la Competencia (2015): PRO/CNMC/001/15: Análisis de la contratación pública en España: Oportunidades de mejora desde el punto de vista de la competencia. (PDF). Recuperado de: http://www.cnmc.es/Portals/0/Notas\%20de\%20prensa/201502_Informe_ContratacionPublica.pdf

IGAE, Ministerio de Economía y Hacienda (2009): Informe general sobre los principales resultados de la ejecución de los planes de control financiero permanente y auditoría pública del ejercicio 2008. (PDF). Recuperado de: http://www.minhap.gob.es/Documentacion/Publico/GabineteMinistro/Varios/09\%2012\%2003\%20Informe\%20CM\%20\%20plan\%202008.pdf

Llinares Cervera, Pedro (2009): Algunas consideraciones sobre los criterios de adjudicación en la Ley 30/2007, de 30 de octubre, de contratos del sector público, a la luz del Derecho comunitario, Contratación Administrativa Práctica. Revista de la contratación administrativa y de los contratistas, núm.82. (En línea). Recuperado en: http://dialnet.unirioja.es/ejemplar/212179

Razquín Lizárraga, Martín María (2011): La Ley de Contratos del Sector Público: balance crítico, aplicación y novedades, en especial, para los entes locales. Revista de Administración Pública, no 186. (PDF). Recuperado de: http://www.cepc.gob.es/publicaciones/revistas $/$ revistaselectronicas? IDR=1\&IDN=1282\&IDA=36258

Yáñez Sánchez, Guillermo (2009): Los contratos menores y la publicidad y concurrencia de empresas. Comunidad de prácticas de la contratación pública. (PDF). Recuperado de:

http://api.ning.com/files/17StHKe5zK4rknkD*Ou8CvDAzjC-

KWt7j55PLXFG*U ${ }^{*}$ 0Q*3xZaNqzcDS-

LAZPPmTQk5M*LSPoEFz5QcW*tAk4nHtMWPHgrn/Loscontratosmenoresylapublicidadyconcurrenciadeempres.pdf 
ción Pública del Instituto Nacional de Administración Pública n 7 (2012).

LLOMPERT BENNÀSSAR, M. "El recibo de salario en formato electrónico". Revista Doctrinal Aranzadi Social n 2 (2007), Ed. Thomson Reuters Aranzadi (BIB 2007\1352).

NIETO ROJAS, P. en "El recibo de salario en formato electrónico", Revista de la Contratación Electrónica n ${ }^{\circ} 114$ (2011), Ed. Dykinson.

SÁNCHEZ MORÓN, M.: "Derecho de la Función Pública". Ed. Tecnos, 8a ed. (2014).

SEMPERE NAVARRO, A.V.: "Entrega del recibo de salarios en papel". Revista Aranzadi Doctrinal, no 11 (2012), Ed. Thomson Reuters Aranzadi (BIB 2012\978). 